\title{
Thoracolumbar Fractures: A Review of Classifications and Surgical Methods
}

\section{Cengiz Gomleksiz', Emrah Egemen², Salim Senturk², Onur Yaman², Ahmet Levent Aydın², Tunc Oktenoglu4, Mehdi Sasani ${ }^{4}$, Tuncer Suzer $^{2}$ and Ali Fahir Ozer ${ }^{2 *}$}

${ }^{1}$ Medipol University, Neurosurgery Department, Istanbul, Turkey

${ }^{2}$ Koc University Medical School, Neurosurgery Department, Istanbul, Turkey

${ }^{3}$ Istanbul Physical Therapy and Rehabilitation Training Hospital, Neurosurgery Department, Turkey

${ }^{4}$ American Hospital, Neurosurgery Department, Istanbul, Turkey

\begin{abstract}
Thoracolumbar fractures are an important topic in spinal surgery. In this article, the instability of the thoracolumbar fracture classifications and surgical treatments are discussed, with a particular focus on treatment concepts that are based on the modern classification systems.
\end{abstract}

\section{Introduction}

Thoracolumbar junction has unique anatomical and biomechanical features because of this region is a transition region from kyphotic thoracal segment to lordotic lumbar segment just like other junctional regions such as servicothoracic and lumbosacral region. Force transmission at these sites is the essential factor for clearly understanding of fracture mechanisms. The kyphotic position of the thoracic spine and the body's center of gravity being located anterior to the spine causes compressive forces to be transmitted anterior to the vertebral body along with a tensile stretch or distraction of the posterior elements. The exact mechanism of individual thoracolumbar traumatic injuries is complex and depends on the exact posture of the spine at the time of force application. An important factor affecting the resistance to flexion, extension, coronal rotation and dislocations is the structure and orientation of the facet joints at this region. The facet joints of the upper thoracic spine have a coronal orientation and resist flexion and extension but, at the lumbar spine facet joints have sagittal orientation and this anatomic feature allows increased flexion and extension [1]. The term of thoracolumbar junction is generally used for T10-L2 vertebral bodies as described by Stagnara et al. [2]. This region especially predisposed for injury due to absence of costovertebral structures that provide additional supporter for vertebral column, and uncompleted transition to the full lumbar lordosis [2].

The management of thoracolumbar fractures is highly controversial, and there is no generally accepted treatment method [3,4]. The main point of discussion is the stability of the vertebral column [5]. This location is the region in which most fracture classifications are defined, and in the literature, there are many treatment options, varying from palliative treatment to early surgical treatment [6-10]. According to turkishspine@yahoogroups.com, 70\% of thoracolumbar fractures are concluded cases, and these cases are mostly burst fractures. This statement suggests that there is no consensus about what we will do for certain fractures. There is several classification systems of thoracolumbar spine fractures defined in literature aiming to provide standardization in surgery of this situation [6,11-14]. The aim of this review is to compose a generally accepted treatment algorithm and to embed the combined approach. The classification systems in the literature are briefly summarized below.

\section{Boehler Classification}

In 1930, Boehler defined a classification for thoracolumbar fractures and divided these fractures in to five categories including compression fractures, flexion-distraction injuries with anterior injury secondary to compression and posterior injury secondary to distraction, extension fractures with injury to anterior and posterior longitudinal ligaments, shear fractures, and rotational injuries $[15,16]$.

\section{Watson-Jones Classification}

In 1938, Watson-Jones described the instability concept and its effect on the treatment of thoracolumbar injuries as an addition of Boehler's study [17]. The importance of Watson-Jones classification is the first classification system that calling attention to the integrity of the posterior ligamentous complex (PLC) is essential for spinal stability. His classification system is consisting of seven fracture types but there are three major patterns: simple wedge fractures, comminuted fractures, and fracture dislocations.

\section{Nicoll Classification}

In 1949, Nicoll improved former classification systems with using anatomical classification [3]. Nicoll defined four specific structures involved in the mechanical stability of the spine: the vertebral body, the disc, the intervertebral joints, and the interspinous ligament [16]. According to his concept, the main determinant factor in stability was the integrity of the interspinous ligament.

\section{Holdsworth Classification}

After 25 years from Nicoll, Holdsworth described a two-column theory in 1963 [18,19]. The main points of him classification are mechanism of injury, presumed forces acting upon the spinal column and the associated paraspinal soft tissues. He defined the posterior column as the "posterior ligamentous complex". According to Holdsworth, spinal stability depends on the integrity of the posterior ligamentous complex. He defined six groups in his study, which included 1000 patients: anterior wedge compression fracture, dislocation, rotational fracture-dislocation, extension injury, burst fracture, and shearing fracture. A compression injury at the anterior column will cause distraction in the posterior column; likewise, compression at the posterior column will cause a distraction injury in

*Corresponding author: Ali Fahir Ozer, Koc University Medical School, Neurosurgery Department, Istanbul, Turkey, Tel: 90 (212) 338-1401, Fax: 90 (212) 338-1559; E-mail: alifahirozer@gmail.com

Received June 30, 2015; Accepted August 10, 2015; Published August 12, 2015

Citation: Gomleksiz C, Egemen E, Senturk S, Yaman O, Aydın AL, et al. (2015) Thoracolumbar Fractures: A Review of Classifications and Surgical Methods. J Spine 4: 250.doi:10.4172/2165-7939.1000250

Copyright: @ 2015 Gomleksiz C, et al. This is an open-access article distributed under the terms of the Creative Commons Attribution License, which permits unrestricted use, distribution, and reproduction in any medium, provided the original author and source are credited. 
the anterior column. Although holdsworth considered flexion fractures as biomechanically stable, subsequent studies showed that if loss of height in anterior vertebral body greater than $40 \%-50 \%$, this may result disruption of posterior spinal elements and lead to instability [20]. Rotational fractures cause a significant strain on the posterior facets and this disruption of the posterior spinal elements makes this fracture naturally instable. Extension injuries place the anterior tissues under tension and posterior elements under compression. Simple extension injuries are generally considered as biomechanically stable if there is no significant ligamentous disruption [1].

\section{Kelly and Whitesides Classification}

Based on the limited number of cases (11 patient) Kelly and Whitesides attempted to redefine Holdsworth's classification scheme [5]. They focused specifically on the anterior column definition and redefined anterior column as the solid vertebral body and posterior column as the neural arch and posterior elements. In contrast to other classification systems, they claimed that burst fractures were inherently unstable. Although their limited case number and experience, this concept was used as reference by subsequent classification systems like Denis and McAfee.

\section{Denis Classification}

Denis described a three-column theory in a study performed in 412 patients using radiological investigation in 1983 [21]. The threecolumn theory of Denis is a mechanical classification more than an anatomical classification. He provided an entirely new viewpoint on thoracolumbar fractures by defining the middle column and provided a better method for analysing thoracolumbar fractures. His classification system remains indispensable even today. According to the Denis classification, the anterior column consists of the anterior portion of the vertebral body, the anterior longitudinal ligament and the anterior portion of the intervertebral disc. The middle column consists of the posterior portion of the vertebral body, the posterior portion of the intervertebral disc and the posterior longitudinal ligament, while the posterior column consists of all of the structures behind the posterior longitudinal ligament [22]. He defined fractures using four groups (compression fractures, burst fractures, seat-belt fractures, and fracture-dislocations) (Figure 1 and Table 1).

\section{McAfee Classification}

McAfee et al. performed CT scans in 100 consecutive cases with instable fractures and fracture dislocations and divided the fractures into six groups: wedge compression fracture, stable burst fracture, unstable burst fracture, chance fracture, flexion-distraction injury, and translational injury [23] (Figure 2). Unlike Denis, these authors

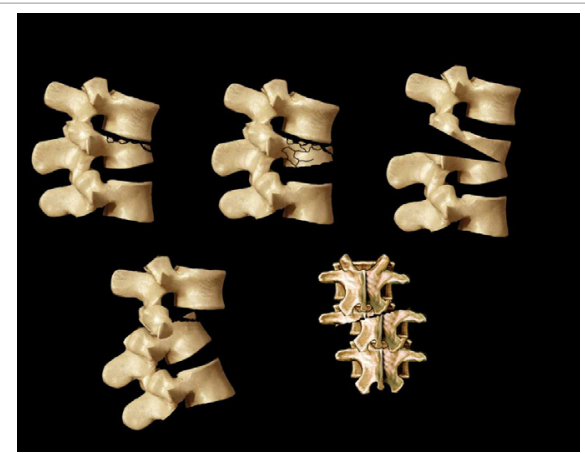

Figure 1: Denis classification A: compression fractures, B: burst fractures, C: seat-belt fractures, D: fracture-dislocation.

\begin{tabular}{|l|l|}
\hline $\mathbf{1}$ & Compression fractures \\
\hline a & Fracture at the frontal plane \\
\hline b & Anterior upper end-plate fracture \\
\hline c & Anterior lower end-plate fracture \\
\hline d & Anterior fracture at both end-plates \\
\hline $\mathbf{2}$ & Burst fractures \\
\hline a & Fracture at both end-plates \\
\hline b & Upper end-plate fracture \\
\hline c & Lower end-plate fracture \\
\hline d & Rotational burst fracture \\
\hline $\mathbf{3}$ & Seat-belt fractures \\
\hline a & One-level bone injury \\
\hline b & One-level soft-tissue injury \\
\hline c & Two levels, including the bone middle column \\
\hline d & Two levels, including the ligamentous middle column \\
\hline $\mathbf{4}$ & Fracture-dislocation \\
\hline a & Flexion rotation \\
\hline b & Shearing \\
\hline c & Flexion distraction \\
\hline & \\
\hline
\end{tabular}

Table 1: Subgroups of the Denis classification.

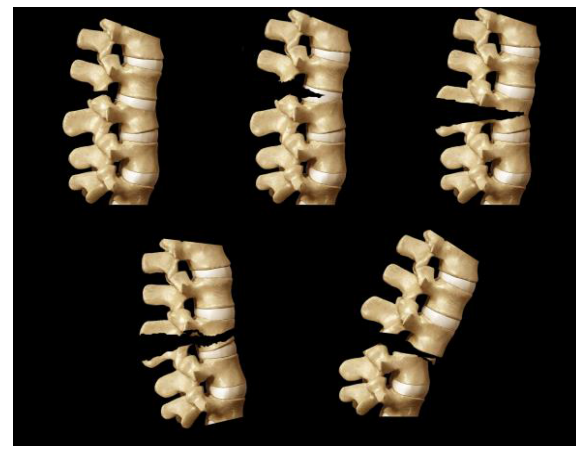

Figure 2: McAfee classification.

reported a "stable" burst fracture. McAfee suggested that some burst fractures could be stable, while in the Denis classification, a burst fracture is an inherently unstable fracture type. According to the authors, the determinative factor in deciding the stability or instability of a fracture is the injury to the posterior elements.

Progressive neurological deficits, kyphosis $\geq 20^{\circ}$, a height loss of more than 50\%, facet joint subluxation, and bone fragments in the spinal canal in a CT with the existence of incomplete neurological deficits were defined as instability criteria by McAfee et al. According to these criteria, all translational and flexion-rotation fracture-dislocations and posterior ligament injuries with kyphosis $\geq 30^{\circ}$ must undergo surgery.

\section{Ferguson-Allen Classification}

In 1984, Ferguson-Allen proposed an "element" concept, in contrast to a column concept, and recommended a mechanistic classification [24]. This classification is the most detailed classification regarding mechanisms in thoracolumbar trauma (Table 2).

\section{McCormack Classification (Load Sharing Classification)}

McCormack et al. reported a load sharing classification in 1994 [25]. This classification was performed using CTs and plain radiograms (Figure 3). This classification is essential for evaluating the anterior column and is performed with consideration for the compressive injuries to the anterior column. It is the most important pathfinder in our management concept. This classification focuses more on the 
Citation: Gomleksiz C, Egemen E, Senturk S, Yaman O, Aydın AL, et al. (2015) Thoracolumbar Fractures: A Review of Classifications and Surgical Methods. J Spine 4: 250.doi:10.4172/2165-7939.1000250

Page 3 of 5

\begin{tabular}{|l|c|}
\hline $\mathbf{1}$ & Compressive flexion \\
\hline $\mathbf{2}$ & Distractive flexion \\
\hline $\mathbf{3}$ & Lateral flexion \\
\hline $\mathbf{4}$ & Translation \\
\hline $\mathbf{5}$ & Torsional flexion \\
\hline $\mathbf{6}$ & Vertical compression \\
\hline $\mathbf{7}$ & Distractive extension \\
\hline & Table 2: Ferguson-Allen classification. \\
\hline
\end{tabular}
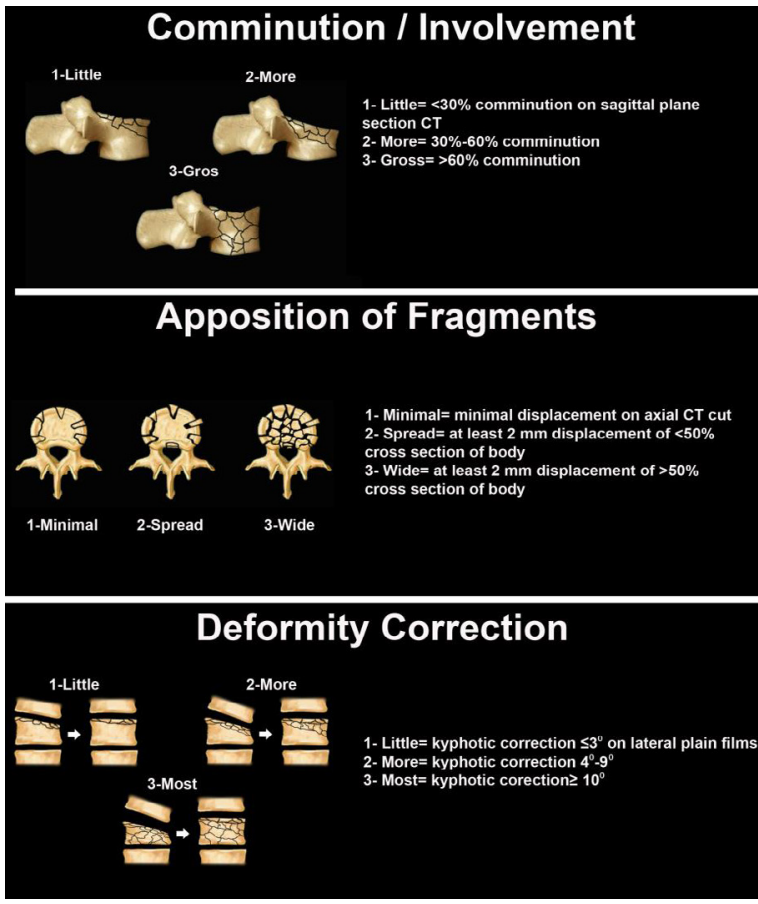

Figure 3: McCormack classification.

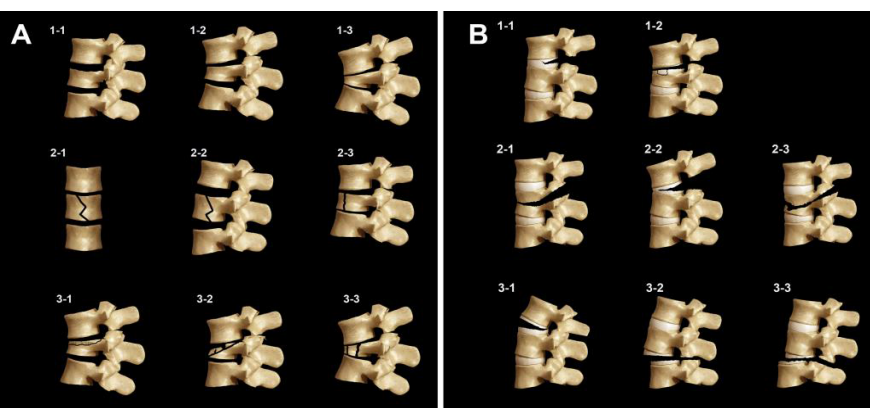

Figure 4: AO classification

location of the fracture in the vertebral corpus that will be treated by a surgeon than on the ligamentous injury.

\section{AO Classification}

This classification is another mechanistic classification and was reported in 1994 by Magerl et al. [26]. This classification is based upon 3 types and 53 injury models according to the analytical evaluation of 1445 cases and the increasing importance of fractures with classical AO rationality (Figure 4 and Table 3 ). This classification evaluates the spinal column as two columns and takes into account the morphological appearance, the direction of the force/mechanism of injury, and increasing injury weight. This classification is highly detailed and easy to use when making evaluations based on CTs and MRIs but is not useful.

\section{Vaccaro Classification (Spine Trauma Study Group- Thoracolumbar Injury Classification and Scoring System-TLICS)}

In 2002 Spine Trauma Study Group (STSG) began to develop a TLICS with the goal of improving on the shortcomings of previous systems to facilitate communication among researchers and clinicians and to optimize patient care [27]. As a result of these attempts, Vaccaro et al. defined a thoracolumbar injury classification and severity score in 2005 [28,29]. This classification takes into account the fracture mechanism, the completeness of the posterior ligamentous complex, and the neurological status of the patient. According to this classification, in cases of less than 3 points, surgical intervention is not suggested. In cases of 4 points, operative or non-operative intervention is suggested, and in cases with 5 points or more, operative intervention is suggested (Table 4).

\section{Evaluation of the Patient}

We mentioned a lot of classification systems for thoracolumbar fracture above. Many of them are historical and unpractical for evaluation a trauma patient in emergency room. We would like to make easy understanding pathology and decision making for ideal surgery.

There are three important issues while evaluating of a patient with spinal trauma in emergency room:

- Severity and location of the ligamentous injury (clinical and radiological evaluation based on classification)

- Disintegration of the vertebral body (load sharing classification,

\begin{tabular}{|c|c|}
\hline Type A & Compression \\
\hline A 1.1 & Endplate fracture \\
\hline A 1.2 & Wedge-compression \\
\hline A 1.3 & Compression \\
\hline A 2.1 & Sagittal split \\
\hline A 2.2 & Coronal split \\
\hline A 2.3 & Pincer fracture \\
\hline A 3.1 & Incomplete burst fracture \\
\hline A 3.2 & Burst-split \\
\hline A 3.3 & Complete burst \\
\hline Type B & Flexion-Extension Fractures \\
\hline B 1.1 & Degeneration from disc surface \\
\hline B 1.2 & Type A + posterior ligamentous injury \\
\hline B 2.1 & Transverse double column \\
\hline B 2.2 & Flexion spondylolysis \\
\hline B 2.3 & Flexion-split + Type A \\
\hline B 3.1 & Extensive extension \\
\hline B 3.2 & Extensive extension-spondylolysis \\
\hline B 3.3 & Backward dislocation \\
\hline Type C & Rotational \\
\hline C 1.1 & Rotation + A1 \\
\hline C 1.2 & Rotation + A2 \\
\hline C 1.3 & Rotation + A3 \\
\hline C 2.1 & Rotation + B1 \\
\hline C 2.2 & Rotation + B2 \\
\hline C 2.3 & Rotation + B3 (shearing) \\
\hline C 3.1 & Shearing/Cut \\
\hline C 3.2 & Shearing- oblique fracture \\
\hline
\end{tabular}

Table 3: AO classification 


\begin{tabular}{|c|c|}
\hline \multicolumn{1}{|c|}{ Points } \\
\hline Fracture Mechanism \\
\hline Compression fracture & 1 \\
\hline Burst fracture & 1 \\
\hline Rotational fracture & 3 \\
\hline Splitting & 4 \\
\hline Neurological Involvement \\
\hline None & 0 \\
\hline Nerve root & 2 \\
\hline Medulla spinalis, conus medullaris; incomplete & 3 \\
\hline Medulla spinalis, conus medullaris, complete & 2 \\
\hline Cauda equina & 3 \\
\hline Posterior Ligamentous Complex \\
\hline Intact & 0 \\
\hline Possibly injured & 2 \\
\hline Injured & 3 \\
\hline
\end{tabular}

Table 4: Vaccaro classification (Spine Trauma Study Group-Thoracolumbar Injury Classification and Scoring System-TLICS).

\section{McCormack)}

- Patient factor (health status, age, body weight, accompanying injuries)

Another point we must consider is whether long-segment or short-segment fusion and $360^{\circ}$ fusion are necessary. Although motion preservation is not important in the thoracic region due to its inherently limited mobility, in the thoracolumbar region, motion must be preserved as much as possible.

There are three important evaluation points:

Is there any translational or ligamentous injury?

What is the vertebral body status according to LSC (Load Sharing Classification)?

What is the neurological status?

Three of classification systems are more helpful to evaluate the patient with thoracolumbar trauma during process of decision-making in emergency room. These are LSC, Vaccaro's classification system and Dennis' classification. Even though there are some objections about Denis classification particularly on burst fractures, McCormack's classification (LSC) completes those weak points.

Dennis' classification is the first determined and simple classification system to understand the mechanism of trauma and trauma related pathologies. The basic concept has been constructed on the middle column. If there is an injury in the middle column, spine should be considered as unstable and surgery would be necessary [21].

We recommend that a thoracolumbar trauma patient would be evaluated based on those three classification systems combined all together for ideal decision-making for treatment.

If there is no ligamentous injury or translation, then posterior short-segment fixation and fusion are appropriate in patients who have 6 or fewer points on the LSC. Six to eight weeks of brace support is necessary to achieve the stiffness of the fusion.

If there is no translational injury or ligament injury and the LSC score is $7-9$ points, an anterior approach is appropriate, and shortsegment fusion is preferred. Six to eight weeks of brace support is sufficient in the postoperative period to allow the fusion consolidation.

Evaluation of these two groups according to Vaccaro's classification corresponds to approximately $5-8$ points.

If there is a ligamentous injury, a seat-belt fracture and the LSC score is 7 points or higher, the short-segment anterior-posterior approach, or in other words, $360^{\circ}$ instrumentation and fusion are recommended.

If there is a translational injury, which often occurs with kyphotic deformity, a $360^{\circ}$ fusion with long-segment fusion is necessary. In kyphotic deformities greater than $30^{\circ}$, the possibility of permanent back pain is very high. Thus, surgical treatment is recommended for such cases. On the other hand, there are several reports in the literature showing that there is no direct relationship between kyphotic deformity and pain.

As a result, 1) kyphosis greater than $30^{\circ}$ with incomplete or progressive neurological deficits requires surgical intervention because this factor directly affects the surgical scoring. 2) It is important that the scoring of the anterior column is evaluated with LSC. The existence of ligamentous injury and translational injury will determine which surgical approach to take: anterior, posterior or a combined approach with short- or long-segment construction. Those patients with kyphosis and ligamentous injury also have up to 8 points according to Vaccaro's classification and probably will have a complicated surgery include anterior and posterior column.

In this article we try to give all classifications according with thoracolumbar trauma and to help the surgeons using these classifications for evaluation of the patients in emergency room.

\section{References}

1. Smith HE, Anderson DG, Vaccaro AR, Albert TJ, Hilibrand AS, et al. (2010) Anatomy, Biomechanics, and Classification of Thoracolumbar Injuries. Seminars in Spine Surgery 22: 2-7.

2. Stagnara P, De Mauroy JC, Dran G, Gonon GP, Costanzo G, et al. (1982) Reciprocal angulation of vertebral bodies in a sagittal plane: Approach to references for the evaluation of kyphosis and lordosis. Spine (Phila Pa 1976) 7: 335-342.

3. Nicoll EA (1949) Fractures of the dorso-lumbar spine. J Bone Joint Surg Br 31: 376 .

4. Verlaan JJ, Diekerhof CH, Buskens E, van der Tweel I, Verbout AJ, et al. (2004) Surgical treatment of traumatic fractures of the thoracic and lumbar spine: a systematic review of the literature on techniques, complications, and outcome. Spine 29: 803-814

5. Kelly RP, Whitesides TE (1968) Treatment of lumbodorsal fracture-dislocations Annals of surgery 167: 705-717.

6. Bucholz RW, Gill K (1986) Classification of injuries to the thoracolumbar spine. Orthop Clin North Am 17: 67-73

7. Reid DC1, Hu R, Davis LA, Saboe LA (1988) The nonoperative treatment of burst fractures of the thoracolumbar junction J Trauma 28: 1188-1194.

8. Bradford DS, McBride GG (1987) Surgical management of thoracolumbar spine fractures with incomplete neurologic deficits. Clin Orthop Relat Res 218: 201-216.

9. Gertzbein SD (1994) Classification of thoracic and lumbar fractures. Spine 19 626-628.

10. Tencer AF, Allen BL, Ferguson RL (1985) A Biomechanical Study of Thoracolumbar Spinal Fractures with Bone in the Canal: Part I. The Effect of Laminectomy Spine 10: 580-585.

11. Louis $R$ (1985) Spinal stability as defined by the three-column spine concept. Anatomia clinica 7 : 33-42.

12. Patel AA, Vaccaro AR, Albert TJ, Hilibrand AS, Harrop JS, et al. (2007) The adoption of a new classification system: time-dependent variation in interobserver reliability of the thoracolumbar injury severity score classification system. Spine 32: 105-110.

13. Oner FC, van Gils AP, Dhert WJ, Verbout AJ (1999) MRI findings of thoracolumbar spine fractures: a categorisation based on MRI examinations of 
Citation: Gomleksiz C, Egemen E, Senturk S, Yaman O, Aydın AL, et al. (2015) Thoracolumbar Fractures: A Review of Classifications and Surgical Methods. J Spine 4: 250.doi:10.4172/2165-7939.1000250

Page 5 of 5

100 fractures. Skeletal radiology 28: 433-443.

14. Mirza SK, Mirza AJ, Chapman JR, Anderson PA (2002) Classifications of thoracic and lumbar fractures: rationale and supporting data. J Am Acad Orthop Surg 10: 364-377.

15. Böhler $L$ (1930) The Technique in the treatment of bone fractures in Griedenund in war Vienna, Austria. Verlagvon Wilheim Maudrich 9-11.

16. Sethi MK, Schoenfeld AJ, Bono CM, Harris MB (2009) The evolution of thoracolumbar injury classification systems. Spine 9: 780-788.

17. Watson-Jones $R$ (1938)The results of postural reduction of fractures of the spine. The Journal of Bone \& Joint Surgery 20: 567-586.

18. Holdsworth $F$ (1963) Fractures, dislocations, and fracture-dislocations of the spine. Journal of Bone and Joint Surgery-British 45: 6.

19. Holdsworth F (1970) Fractures, dislocations, and fracture-dislocations of the spine. J Bone Joint Surg Am 52: 1534-1551.

20. Panjabi MM, Brand RA, White AA (1976) Three-dimensional flexibility and stiffness properties of the human thoracic spine. J Biomech 9: 185-192.

21. Denis $F(1983)$ The three column spine and its significance in the classification of acute thoracolumbar spinal injuries. Spine (Phila Pa 1976) 8: 817-831.

22. Wood KB, Khanna G, Vaccaro AR, Arnold PM, Harris MB, et al. (2005)
Assessment of two thoracolumbar fracture classification systems as used by multiple surgeons. The Journal of Bone \& Joint Surgery 87: 1423-1429.

23. McAfee PC, Yuan HA, Fredrickson BE, Lubicky JP (1983) The value of computed tomography in thoracolumbar fractures. J Bone Joint Surg Am 65: 461-473.

24. Ferguson RL, Allen BL (1984) A mechanistic classification of thoracolumbar spine fractures. Clin Orthop Relat Res 189: 77-88.

25. McCormack T, Karaikovic E, Gaines RW (1994) The load sharing classification of spine fractures. Spine (Phila Pa 1976) 19: 1741-1744.

26. Magerl F, Aebi M, Gertzbein SD, Harms J, Nazarian SA (1994) Comprehensive classification of thoracic and lumbar injuries. European Spine Journal 3: 184-201.

27. Kepler CK,Felte RF, Rihn JA (2012) Current Concepts: Classification of Thoracolumbar Fractures. Seminars in Spine Surgery 24: 210-215.

28. Vaccaro AR, Zeiller SC, Hulbert RJ, Anderson PA, Harris M, et al. (2005) The thoracolumbar injury severity score: a proposed treatment algorithm. J Spinal Disord Tech 18: 209-215.

29. Vaccaro AR, Lehman RA, Hurlbert RJ, Anderson PA, Harris M, et al. (2005) A new classification of thoracolumbar injuries: the importance of injury morphology, the integrity of the posterior ligamentous complex, and neurologic status. Spine 30: 2325-2333. 